Case Report

\title{
A case study of post-auricular persistent mastoid cutaneous fistula closure by anteriorly based temporalis muscle flap and tempero-mastoid fascio-cutaneous-periosteal flap
}

\author{
Rajkumari P. Khatri* \\ Dr. Rajkumari ENT and Head and Neck Oncology Centre, Indore, Madhya Pradesh, India
}

Received: 08 July 2021

Accepted: 16 August 2021

\section{*Correspondence:}

Dr. Rajkumari P. Khatri,

E-mail: raj.sachdeva@rediffmail.com

Copyright: (c) the author(s), publisher and licensee Medip Academy. This is an open-access article distributed under the terms of the Creative Commons Attribution Non-Commercial License, which permits unrestricted non-commercial use, distribution, and reproduction in any medium, provided the original work is properly cited.

\begin{abstract}
Post-auricular cutaneous mastoid fistula (PAMCF) is a rare complication of chronic otitis media (COM), following complicate mastoid surgery and very rarely following congenital cholesteatoma. The failure rate with simple closure is high due to necrotic skin edges. Therefore several techniques for the closure of this fistula have been described. Post aural fistula after canal wall down (CWD) mastoidectomy can be successfully treated by fistula tract excision and obliterating the mastoid cavity. A 45 year old woman presented with discharging PAMCF, 10 years following radical mastoidectomy surgery. It was due to non-compliance of the patient, as she had not gone for follow up for 10 year following radical mastoidectomy. The temporo-mastoid fascio-cutaneous-periosteal advancement flap is effective for proper closure of the fistula and obliteration of the cavity by conchal cartilage along with anteriorly based vascularised pedicled temporalis muscle flap to ensure the viability of the flap and preventing the necrosis of the skin edges, henceforth the recurrence of the fistula.
\end{abstract}

Keywords: Mastoid-cutaneous fistula, Fistula closure, Complication of mastoidectomy, Flap, Post-aural fistula

\section{INTRODUCTION}

PAMCF is a rare complication of the squamous variety of COM, complicate following mastoid surgery and a rare complication of congenital cholesteatoma. The failure rate with simple closure is high due to necrotic skin edges. ${ }^{1,2}$ Therefore several techniques for the closure of this fistula have been described.

Post aural fistulas after CWD mastoidectomies can be successfully treated by fistula tract excision and obliterating the mastoid cavity. The incidence of the discharging mastoid cavity after a CWD procedure is between $10-66 \% .^{3}$ At the end of the CWD procedure, the cavity is polished with a diamond bur which smoothens the cavity but devascularize it, compromising its epithelial regeneration. The size of the discharging surface decreases drastically after cavity obliteration and the epithelial regeneration of the remaining surface is fastened if a vascular pedicled graft is used. ${ }^{3}$ The rate of healing of the cavity becomes faster after obliteration. ${ }^{4}$ The main disadvantage of cavity obliteration is a failure of early detection of cholesteatoma recurrence and a remote risk of intracranial complications. ${ }^{5}$

Post-aural discharge and cosmetic applications are the complications that demand closure. PAMCF is commonly unilateral but bilateral occurrence complicating cholesteatoma has been reported. ${ }^{1}$

The inverted skin surrounding the fistula often undergoes necrosis, with epithelial migration and fusion with epithelial lining of the mastoid cavity, so mastoid cutaneous fistulas tend to heal very slowly or doesn't heal spontaneously at all and surgical closure is indicated. ${ }^{6}$ 
Several surgical techniques have been proposed for the closure of mastoid cutaneous fistulas. These procedures further pose a challenge to the surgeon due to the lack of availability of tissues for reconstruction. The scalp tissues are already scarred and the temporalis fascia has already been used up. ${ }^{7}$ So newer flap options need to be sought to obliterate the cavity.

\section{CASE REPORT}

A 45 year female presented with a history of discharge from the postauricular region for 6 months not responding to conservative treatment and also complained of hard of hearing from the right ear (RE) and decreased hearing from the left ear (LE). She had a past history of surgery on the RE 10 years back, for the management of discharging $\mathrm{RE}$, which had been discharging since childhood. There was no improvement in the hearing from the right ear following surgery. General examination was normal.

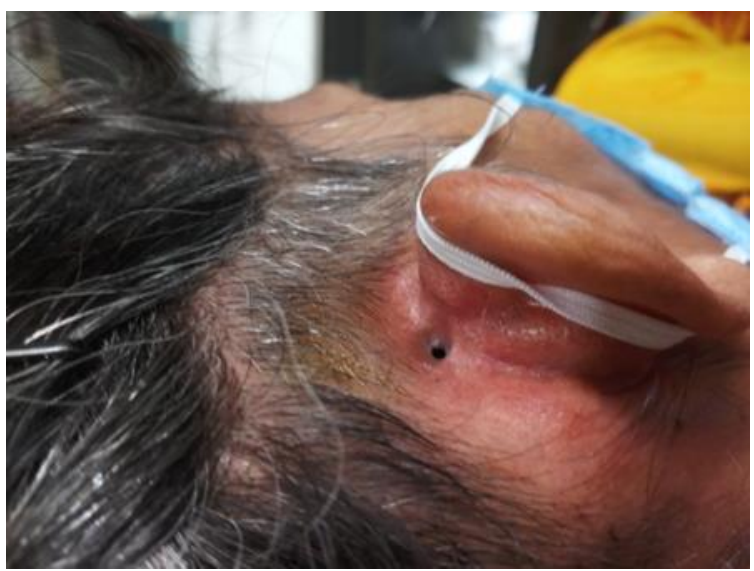

Figure 1: Post-aural mastoid cutaneous fistula.

Local ENT examination revealed dry LE with large central perforation with intact ossicular chain and RE revealed narrow external auditory canal (EAC), full of squamous debris and purulent discharge, active discharging fistula in the post-auricular region which is approximately $1 \mathrm{~cm}$ in diameter and surrounding skin was inflamed as seen in Figure 1. Facial nerve was normal.

Re-examination was done under the microscope, with complete clearance of squamous debris and purulent discharge from the EAC and middle ear (ME) mastoid cavity. No cholesteatoma was seen. The meatal opening appeared to be narrow and so all squamous debris and wax kept on accumulating and got secondarily infected with fistula formation in the post-auricular region.

The CT scan of the temporal bone revealed soft tissue opacification of the entire right mastoid cavity, ME and EAC. There appeared complete resorption of the ME ossicles. The tympanic segment of the facial nerve was exposed. The left middle ear cavity and ossicles were normal.

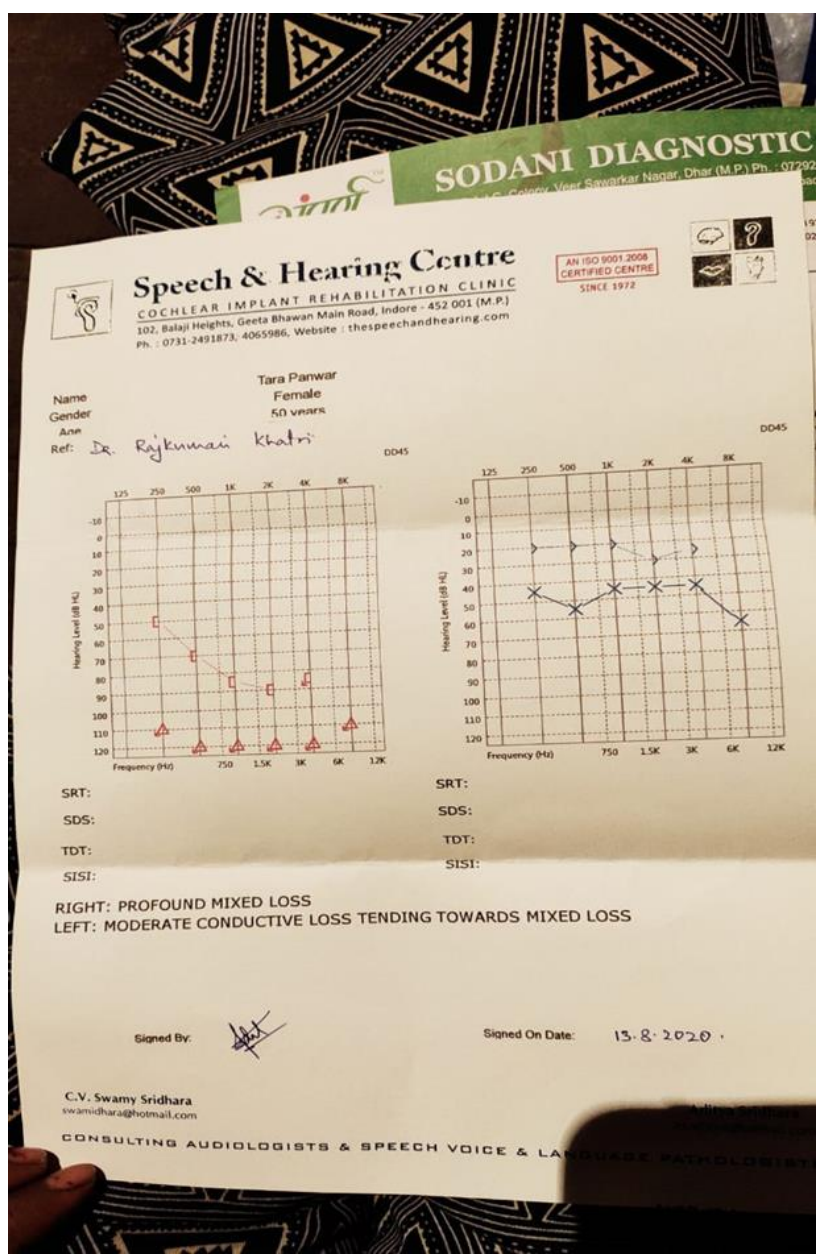

Figure 2: PTA.

After conservative treatment and aural toileting, within 45 days the RE became dry. PTA revealed bilateral hearing loss as shown in Figure 2.

As RE has profound hearing loss and LE was dry for many years, so type I tympanoplasty was done for LE. Post-op was uneventful.

The RE remained dry, with no recurrence of cholesteatoma in 12 month follow up period, the decision was taken to explore the RE with the closure of the fistula.

Post auricular incision was given encircling the fistulous opening. Anterior and posterior flaps were elevated. The fistulous tract extending into the mastoid cavity near the sino-dural angle was removed in toto. The mastoid cavity was drilled and edges were smoothened. Meatoplasty with excision of the conchal cartilage was done, conchal cartilage was used to obliterate the mastoid cavity. The ME lining was healthy, temporal fascia graft used to cover ME and obliterated mastoid cavity. 
An anteriorly based temporalis muscle flap was used to vascularize the skin and underlying fascia graft and sutured to the lower myocutanous raised flap. As the skin was very thin and flappy, it was possible to do primary closure of the skin flaps without any tension, by adequate mobilization of the flap posteriorly and superiorly by extending the incision superiorly in the temporal region.

The patient was discharged the next day, with antibiotics prescribed for a week. The patient was followed up for 6 months and showed good wound healing with no recurrence of the fistula.

\section{DISCUSSION}

Mastoidectomy procedures are divided into two types, intact canal wall (ICW) and CWD technique.

The disadvantages associated with CWD mastoidectomy included lifelong mastoid care and the possible recurrence of discharge. ${ }^{6}$

In the present case, there was a collection of epithelial debris and wax which got secondarily infected leading to fistula and discharge as the patient had not gone for follow up after mastoidectomy. The EAC meatus was very narrow, which had further worsened the condition.

The suppuration in the remaining tissues and obstructive mechanical factors enhances the accumulation of the debris in the cavity-causing discharge. Though, incomplete disease clearance during mastoidectomy has been recognized as a common cause of failure in patients, with or without cholesteatoma. ${ }^{3}$

Despite various new surgical techniques for the management of chronic suppurative otitis media (CSOM), many patients presented at a late stage with complications like fistulas. $^{7}$

Several methods of cavity obliteration were proposed, which included free and pedicled skin grafts, temporalis muscle flaps, bone chips, bone pate, cartilage grafts, nonabsorbable grafts that failed in most of the cases as they necrosed and sloughed off resulting in persistently discharging cavity and problems at the donor site. ${ }^{3}$ These grafts failed because of a lack of adequate vascularity within the cavity which prevented the integration of the grafts and synthetic substances. ${ }^{9}$

The flaps of the fascia of the scalp which included epicranial aponeurosis and loose areolar tissue were also used alone or along with pedicled temporalis muscle flaps. Because of the rich vascularity of the scalp, this was a simple reliable method of cavity obliteration. The scalp flaps were supplied by superficial temporal and posterior auricular arteries. ${ }^{5}$ The muscle and fascial grafts shrunk and formed a fibrous coating that supported the growth of epithelium from the edges. ${ }^{4,5}$
The neck skin like the facial skin had very good vascularity such fascio-cutaneous flap was effective in the obliteration of the mastoid cavity in a patient of recurrent PAMCF.

Daud et al utilized the postauricular fascio-cutaneoperiosteal advancement flap with Burow's triangles following excision of the fistula margin for the closure of the fistula. ${ }^{8}$

Gibb et al had described the use of a rotation pedicled flap, entitled the Singapore swing, comprising temporalis fascia and mastoid periosteum, was presented as a new method of promoting healing in open mastoid surgery for chronic ear discharge.

\section{CONCLUSION}

PAMCF resulting as a complication of CWD mastoidectomies can be treated successfully by combined local advancement fascio-cutaneous-periosteal flaps and vascularised pedicled muscle flaps especially when blood supply appears to be compromised. These flaps are safe, well-vascularized, malleable, and easily adaptable to the bone cavity. Long-term results are good with good fistula healing and reduced cavity problems.

\section{ACKNOWLEDGEMENTS}

I am highly thankful to Dr. V. S. Nanduri for providing guidance in writing the article.

Funding: No funding sources

Conflict of interest: None declared

Ethical approval: Not required

\section{REFERENCES}

1. Bhat KV, Udayashankar SG, Venkatesha BK, Kumar P. Bilateral attico-antral chronic suppurative otitis media presenting as bilateral cutaneous mastoid fistulas. Ear Nose Throat J. 2009;88(10):1-3.

2. Choo JC, Shaw Cl, Schong YC. Postauricular cutaneous mastoid fistula. J Laryngol Otol. 2004;118(11):893-4.

3. Naik SM, Naik SS. Postoperative mastoid fistulas managed by fistulous tract excision and cavity obliteration by epicranial aponeurosis and temporalis fibromuscular flaps. Pakistan J Otolaryngol. 2013;29:59-61.

4. Franco D, Franco T, Gonsalves LFF, Silva CSC. Galeal flaps for mastoid fistula. Rev Bras Otorrinolaringol. 2001;67(6):852-7.

5. Wadhwa V, Anand TS, Kumar S. Periosteotemporofascial flap for cavity obliteration. Ind $\mathrm{J}$ Otolaryngol Head and Neck Surg. 2003;55(3):170-4.

6. Saki N, Araghi S, Abshirini H, Nikakhlagh S. Postauricular advancement flap for closure of 
persistent mastoid cutaneous fistula. Biomed Pharmacol J. 2015;8:795-7.

7. Vathulya M, Malhotra M, Varshney S. Extra dimension of fascio-cutaneous flap in the surgical management of postaural fistula, a complication of chronic otitis media-squamous type. Int $\mathbf{J}$ Otorhinolaryngol Head Neck Surg. 2017;3(2):41922.

8. Olusesi AD, Opaluwah E. Postauricular advancement fascio-cutaneo-periosteal flap for closure of mastoid cutaneous fistula. Otolaryngologia Polska. 2014;68(5):276-80.

9. Gibb AG, Tan KK, Sim RST. The Singapore swing. J Laryngol Otol. 1997;111(6):527-30.

Cite this article as: Khatri RP. A case study of postauricular persistent mastoid cutaneous fistula closure by anteriorly based temporalis muscle flap and tempero-mastoid fascio-cutaneous-periosteal flap. Int J Otorhinolaryngol Head Neck Surg 2021;7:1551-4. 